\title{
The Analysis of a Learning Management System from a Design and Development Perspective
}

\author{
Abdallah Ahmed Hassan Alia
}

\begin{abstract}
The use of information technology as a means of educating students has become a popular trend. For this purpose, a special type of content management system was used, called learning management systems (LMS) and course management systems (CMS). Often all of these platforms offer similar features and users cannot choose the one that best suits them. This article proposes an analysis of the usability and functionality of software in LMS frameworks. Based on the integration of parallel work on the same database, you can automatically synchronize and manage accounts, users, sessions, and distribute (session and user) easily. There is no need to manually enter data in two different systems. This increases the value of the learning management system used by improving time and accuracy. By first, reducing the time creating learning materials within the LMS. Second, the accuracy in creating the learning materials within the LMS. Third: Accuracy in distributing students and teachers to the course. Fourth, configure the class room inside the LMS that matches the CMS one hundred percent. It includes subjects, departments, faculties and users (students and teachers). The contribution of this paper provides a rich recent direction of software methodologies for web-based learning management systems from a design and development perspective.
\end{abstract}

Index Terms-Integrated, education, frameworks, social media, LMS analysis, content management, software engineering.

\section{INTRODUCTION}

\section{A. Learning via e-Learning}

Learning is a process by which an individual assimilates information, ideas, values, knowledge and skills are acquired. Learning activities can be classified to learning formal and non-formal.

Formal learning is a learning that occurs in an organized and structured environment (such as in an education or training institution or on the job) and is explicitly designated as learning (in terms of objectives, time or resources). Formal learning is intentional from the learner's point of view. It typically leads to certification. Learning that occurs in an organized and structured context (in a school/training centre or on the job) and is explicitly designated as learning (in terms of objectives, time or learning support). Formal learning is intentional from the learner's point of view, it typically leads to certification [1].

Informal learning is a learning resulting from daily activities related to work, family or leisure. It is not organized

Manuscript received July 15, 2021; revised September 27, 2021.

The author is with the Department of computer science, Information Technology College, Zarqa University-Jordan, Jordan (e-mail: abualia@zu.edu.jo). or structured in terms of objectives, time or learning support. Informal learning is in most cases unintentional from the learner's perspective [2].

Nowadays, using a new technology is various aspects of our daily life leads to a new type of learning called e-learning. E-learning is the process of providing education over the internet and computers. Some means of e-learning include electronic multimedia, such as audio, text, images, video, etc. Each produces an immense learning and enjoyable atmosphere for the student. Also, e-learning isn't bound to the classroom. This promotes a greater level of distance learning for everyone involved. It is a great option for those who can't afford their time and circumstances to attend lectures or live near a university. It is a self-paced and asynchronous process of learning [2].

Horton defined e-learning as any use of web and internet technologies to create learning experiences and enable people to learn anytime and anywhere [3].

Clark also said e-learning method of using digital device such as a computer or mobile device that is intended to support learning. Such a device stores and transmits lessons on CD-ROM, local internal or external memory, or servers on the internet, uses media elements such as words and pictures to deliver [4].

E-learning activities can be classified according to their time dependence as:

1) Synchronous: needs to learn the need for a student and teacher at the same time, via intranet or internet.

2) Asynchronous: e-learning in which teachers and students are involved in learning activities at different times, through Internet or intranet but their interactions are not done in real time [4].

The most common teaching methods in education is the asynchronous one, and there are many educational institutions use many education systems including learning management systems, and other sources of online learning, video conferencing technologies, other audio and visual technologies.

\section{B. E-Learning Platform}

E-learning platform is a software application that integrates different management tools, communication, evaluation and monitoring, etc. The e-learning platform aims at providing technological support to teachers and students to optimize the various phases of the teaching-learning process, either the educational process completely remote classroom or mixed nature. Furthermore, it combines both modes in different proportions [5], [6].

Depending on the functionalities and the goals of the e-learning platform we can classify them as follows: 


\section{1) Learning management system (LMS)}

LMS to be a system that works on the educational process management and learning management tools on the Internet or internal network. It connects the contents of learning and learners to gather. It manages users, educational materials and learning events. It manages learning progress and track performance and manages administrative tasks [7].

LMS refers to systems that support the management of learning activities as well as course related administrative activities. Features include discussion or chat space, test creation and delivery tools, file sharing tools, student and course management features, assignment and grade management utilities, and others. LMS is a software system designed to facilitate administrative tasks as well as student participation in e-learning materials [8].

LMS to the classroom and its activities online; There by, connecting students to each other and their instructors. Empowering web-based sharing of research materials, library resources, and even text books. They are integrating learning activities with administrative systems. Through LMS technology, faculty members can amplify their teaching with powerful online tools. Students can use these tools to increase their contact with teachers. By adopting such technology across various educational sectors [9].

LMS includes features like discussion forums, chat, management file, assessments management, wiki, content management, video conferencing facilities, messaging systems, rating systems for courses, and others [10].

Now days, LMS can also be called a learning portal (or a performance portal) and can look like a typical intranet or website. There are a lot of open source e-learning platforms available on the web. Many of which provide really competent features. Some of LMS open source system are: Moodle, E-front, Atutor, Dokeos and Docebo. The Moodle is a popular LMS.

A LMS is a software package that enables the management and delivery of course content and resources to students [11].

Most LMSs are usually web based systems that allow students to access learning materials from anywhere and at any time [11].

Typically, LMSs allow students to register for a particular course and they provide facilities for instructors to create and deliver content, monitor participation of students and assess their performance [12].

Registered students can use LMS's interactive features such as threaded discussion forms, video conferencing facilities, and messaging systems. The moodle is one of the best learning management systems, Nadire Cavus work compared moodle system with five other e-learning systems. His study shows that moodle is one of the best system [13].

Ajlan, also provedinhis study that the moodle system is one of the best system e-learning [14].

\section{2) Content management system (CMS)}

CMS is a system used to manage the content, and contain the most basic functionality. CMS is an easy and collaborative environment and used in creation of documents, lessons and other content. CMS system may also provide tools allows publishing, editing, modifying content and maintenance by combining rules, processes, from a central interface. CMS a repository for content, the content could be textual data, documents, movies, pictures, phone numbers, and/or scientific data. Where it is needed to generate the content within the system. Among the communication tools can be found forums, email and chat [15].

CMS is a collection of software tools providing an online environment for course interactions. That enables the instructor or student to create online course and without having to handle HTML or other programming languages [15].

A CMS includes a variety of online tools and environment. They are student information system, registration system, and academic information system, as show in Fig. 1.

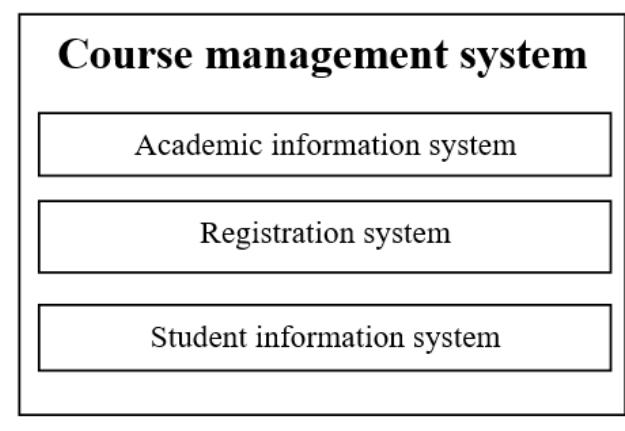

Fig. 1. Course management system environment.

CMS used in educational institutions for the registration of students, teachers and materials and faculties and departments data and it works on the organization of the instruction work of the foundation. As an operating environment within university or schools environment, and taking important role in the academic enterprise of teaching and learning. This environment of software tools interactive with some in educational institutions [16]. CMS have become part of the higher education landscape and likely to occupy an ever increasing and prominent role in teaching and learning process [17]. CMS was selected because of the rich features, the software provides for learning, registration course student and teacher in classroom. CMS integration block which would simplify the integration process using any version of LMS.

Use of new technology in the institutions, to improve the quality of teaching and learning, through the development of learning content management systems (LMS, LCMS), to gain access to educational content and easily educational activities, and the increasing spread of the networks of social interaction. It has an important role in social interaction, and the sharing of resources increasingly to learn, as well as the ideas and opinions through discussions and presentations, blogs, comments, etc. They offer a range of features that must be available in e-learning systems in the future:

1) Formal methods and informal education and the integration of the shift toward collaborative learning.

2) Improve the control of the students.

3) Connect or integrate LMS with well-known warehouse where learning objects are stored. This way you will create a kind of super data base where LMS will become a kind of distribution warehouse, to search directly, the full potential on the Internet transmission of educational material between e-learning systems. 
4) Full re-use of objects-based learning on the Web to learn from one system to another.

5) Possibility of creating shared libraries or media with stores to learn from the different environments LMS.

6) Installation of external functions that are not products of the company which owns the LMS.

7) LMS integration with ERP. ERP (enterprise) is a system that allows the integration of services through a single object resource planning. CRM (customer relationship management) is a system that helps manage customer relationships.

8) Improve the relationship between the LMS with the contents of the media, the balance between control and freedom of LMS customers to enable them to join the quality and the quality of learning, activities and support [18].

Development the related tools with e-learning, and relationship with other concepts. Such as knowledge management, human resources management, enterprise resource planning and information technology. The advantage is that he is provided us with a set of ideas that contribute to the development of e-learning systems, by integrating e-learning systems with other systems [19], [20].

A group of researchers studied the subject of interaction and cooperation in the learning management system, through a set of tools that support the synchronous and asynchronous interaction between students in the learning management system. The results showed that the students used the learning management system (LMS) successfully and achieved interaction and cooperation between them, through Use the following tools: ads, chat, discussion, email, and wikis. But there were restrictions on interaction and cooperation between students by the educational institution management.

\section{3) Learning content management systems (LCMS)}

LCMS Produced from the integration of LMS and CMS in a single environment. Aim primarily at managing the delivery of course content. The LCMS facilitates organization of content from authoring tools, and presentation of this content to students via the LMS [21], [22].

Often used interchangeably with LCMS is the Virtual Learning Environment (VLE). VLE with its focus on the learning space and on the idea of a platform that supports the whole range of learning activities as a standalone integrated virtual environment. Such as Blackboard, Saba, ATutor, Claroline, Dokeos and Moodle [23].

\section{ReSEARCh Methodology}

The issue of social requirements in the e-learning depends on the improvement of collaborative activities, and the impact of social requirements is produced through the effective cooperation between the members. In order to ensure effective cooperation and participation, we need to software engineering to gather information in order to discover the social requirements in e-learning. Social aspects of software engineering based on social requirements such as motivation, bonding. Social requirements increase social interaction in e-learning. You can improve social interaction in e-learning by increasing social requirements in the design of e-learning system, and through the requirements required by users. The contents of the e-learning and social requirements help to increase the use of e-learning system.

\section{A. Requirements Elicitation Process}

In this paper, we will use the requirements elicitation spotted social requirements, according to the requirements elicitation process by understanding the application domain, identifying the sources of requirements, analyzing the stakeholders and selecting the techniques, approaches, tools to use, as show in Fig. 2 [24].

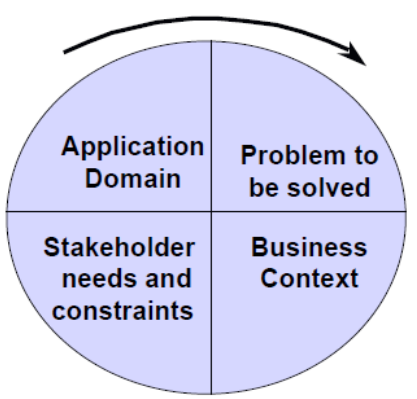

Fig. 2. Level requirement elicitation.

Understanding the application domain: Learning Management System (LMS) refers to systems that support the management of learning activities as well as course related administrative activities. features include discussion or chat space, test creation and delivery tools, file sharing tools, student and course management features, and assignment and grade management utilities, others.

Identifying the sources of requirements (problem to be solved):

- Show the weakness of the current use of traditional education and e-learning system.

- Lacks of using the advantages of the social requirements, in e-learning systems.

\section{B. Analyzing the Stakeholders by Interview Them}

We conducted an interview with stakeholders to learn social requirements related to e-learning system. Through the interview, which was conducted, it shows that stakeholders need a set of requirements that help to facilitate their work on the e-learning system. The social requirements requested by the stakeholders are divided into two types:

The issue of the electronic processing of virtual classrooms:

Get rid of manual and paper-based business in the e-learning system processing, used in processing electronic virtual classrooms similar traditional education in classroom. These as actions take time and effort during the processing e-learning system.

\section{The Issue of Social Interaction}

The social interaction in e-learning system with a limited number of activities used within the system (example: messaging, chat, forums, wiki). These activities are confined within the e-learning system environment, any interactions it's closed on itself within the course and the members of its participants in course. Course need to pre-processing of the teacher, until they are dealing with the course. 
During the interview stakeholders pointed to the need to increase social interactions. Because of the interactions between students and teachers be present inside the classroom in the traditional education (classrooms). These interactions expire once they are out of the framework of the educational institution. Pointed stakeholders that they need to be continued interaction and cooperation between students and teachers outside the classroom (traditional education). The local community and global in the education process. In the following main questions and answered by stakeholders:

- How to form a traditional classroom?

The stakeholders answer that are formed by a group of systems within the institution known as the admission and registration systems.

- How to increase the interaction within the e-learning systems?

The stakeholders answer through an increase in the presence of media and social networks. Where social requirements have these requirements demanded by everyone in the various fields of entertainment, advertising, education, building social relationships and communication.

- How to form the electronic classroom?

The stakeholders' answers through a series of stages, including:

1) Data entry user (student, teacher, manager).

2) Data entry colleges, departments and course.

3) Registered users for course data entry.

4) Distribution of roles to users.

These stages are the same stages that occur in the processing of traditional education, but in different operational environments and how to deal with the data as both the e-learning systems and materials management systems, have different installation at how working with data. Where we are in the process of e-learning systems processing using excel files under extension (CSV). This requires time and effort in the process of file processing. The interview, which was conducted, helped to define the requirements that we need to build a new model.Through the use of requirements elicitations that are part of the software engineering that will contribute to the development of systems, and also use the re-use requirements. Which aims to use existing systems to create a new system serves the stakeholders. Also ease the material cost. It is also working on the unification of user's systems. For example, unify password between the e-learning and management system materials. Also recorded course by users and retention on users' roles. This leads to increased demand for the use of e-learning system by teachers and students. The reason for this is due to move away from manual work in preparing virtual classrooms.

Through the interviews that were conducted with the management team of e-learning systems, have been reached the following components, which are considered among the most important components that the e-learning system must provide. The following components are found as the most essential for the system to provide. It shall overcome problems related to manual and paper-based activities, automate most of the feasible tasks such as course management system, social Requirements, and provide ease of use of the learning management systems for the members.so that include my system Course Management System (CMS)and Social Requirements (SR).

Selecting the techniques, approaches, tools to use:

The research approach is integration approach, the approach which works to build a new model, where done the build the new model in two steps.

First step: Integration of learning management systems with electronic course management system process. This carried out through a set of processes as follows:

- Study a current of open source learning management systems and course management system.

- Specify features of learning management systems and classification features.

- Specify features of course management system and classification features.

- Built Learning Integration Course (LIC) integration between LMS and CMS.

Second step: Integration of LIC with the tools of social media process. This carried out through a set of processes is as follows:

- Study the most important of the social media.

- Chose best the social media can be integration.

- Built Learning Integration Course Social (LICS) integration between Learning Course Management System (LCMS) and social media.

\section{IMPLEMENTATION TECHNIQUE}

The e-learning structure depends on traditional education (CMS) and social networks systems, known as social requirements. In this thesis, the one step we suggested a model for integration of traditional education systems (CMS) and social networks systems with learning management system. This model will benefit from current open source system components to build electronic education system, integrated, collaborative and interactive.

Through prototype model design, depend on integration the e-learning components with traditional education systems components (CMS). The second step in this model integrates the prototype model with social networking components, as shown in the following Fig. 3.

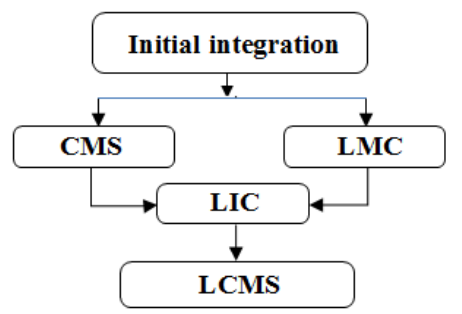

Fig. 3. Work flowchart.

The proposed model consists of two steps as shown in Fig. 3:

Step 1 initial integration: this step integrates learning management system components with the courses management systems components.

Step 2 social integration: this step integrates system components resulting from the first step with social networking components.

The first stage of the integration process consists of using 
two open source systems (software applications) LMS and CMS

The two systems are merged from a new Learning Integration Learning Module Course (LIC), which allows CMS authenticated users to access the LMS through a link on the LMS page without having to re-authenticate again within the CMS.

Moodle (Modular Object Oriented Dynamic Learning Environment) is LMS was selected because of the rich features which it provides for the management of the e-learning process and also because it is used by university to manage the delivery of courses and course contents to students complementing their classroom learning. There are also a lot of researches and studies, refer to Moodle system as one of the best open source systems. The Moodle learning platform is based on strong pedagogical principles, providing a private learning space for you to design online courses with flexible content and communication tools or activities so your students are constantly experiencing feedback and usually a web application [21].

Course Management system (CMS) was selected because of the rich features the software provides for learning, registration course student and teacher in classroom and also because there existed a CMS integration block which would simplify the integration process using any version of LMS.

\section{A. Learning Management Systems}

Table I represents the basic features contained in learning management system where the twelve features are used. All the features contain a set of tools that reflect the nature of the work feature. So that will be used the main features show as in Table I in create classification features.

TABLE I: MAIN FEATURES IN LMS

\begin{tabular}{|c|c|c|}
\hline \multicolumn{3}{|c|}{ Features LMS } \\
\hline No. & Features & Tools Used In Features \\
\hline 1 & Users & Accounts, Permissions \\
\hline 2 & Courses & $\begin{array}{l}\text { Add/edit courses, Course default settings, Course } \\
\text { request }\end{array}$ \\
\hline 3 & Grades & $\begin{array}{l}\text { General settings, Grade category settings, Grade } \\
\text { item settings, Scales, Letters }\end{array}$ \\
\hline 4 & Location & Location settings, Update time zones \\
\hline 5 & Language & $\begin{array}{l}\text { Language settings, Language customization, } \\
\text { Language packs }\end{array}$ \\
\hline 6 & Plug-in & $\begin{array}{l}\text { Activity modules } \\
\text { Assignment, Book, Database, Folder, Forum, } \\
\text { Glossary, IMS content package, Lesson, Light box } \\
\text { Gallery, LTI, Page, Quiz, File, SCORM package, } \\
\text { URL, Workshop }\end{array}$ \\
\hline 7 & Security & $\begin{array}{l}\text { IP blocker, Site policies, HTTP security, } \\
\text { Notifications, Anti-Virus }\end{array}$ \\
\hline 8 & Appearance & $\begin{array}{l}\text { Themes, Calendar, Blog, Navigation, HTML } \\
\text { settings, Media embedding, Docs, Default My } \\
\text { page, Default profile page, Courses, AJAX and } \\
\text { JavaScript, Manage tags, Additional HTML }\end{array}$ \\
\hline 9 & Front page & $\begin{array}{l}\text { Front page settings, Front page roles, Front page } \\
\text { filters, Front page backup, Front page restore, Front } \\
\text { page questions }\end{array}$ \\
\hline 10 & Server & $\begin{array}{l}\text { System paths, Support contact, Session handling, } \\
\text { Statistics, HTTP, Maintenance mode, Cleanup, } \\
\text { Environment, PHP info, Performance, Hubs, } \\
\text { Update notifications }\end{array}$ \\
\hline 11 & Reports & $\begin{array}{l}\text { Comments, Backups, Config changes, Course } \\
\text { overview } \\
\text { JMeter load testing, Logs, Live logs, Question } \\
\text { instances } \\
\text { Security overview, Statistics, Spam cleaner }\end{array}$ \\
\hline 12 & Development & Debugging, PHPUnit tests, XMLDB editor \\
\hline
\end{tabular}

Table II represents a classification learning management system. Classification features learning management system into three main classification (administrator, communication and learning). Each classification contains a set of features based on the nature of the work features. So that will use the first classification (administrator) to create integration learning management system with traditional education systems (CMS) and to create administrator classification framework based on feature common between LMS, CMS, as shown that in Table III.

TABLE II: CLASSIFICATION FEATURES IN LMS

\begin{tabular}{|c|c|c|}
\hline No. & Classification & Features \\
\hline 1. & Administrator & $\begin{array}{l}\text { Users, Courses, Grades, Location, Language, } \\
\text { Plugins, Security, Appearance, Front page, } \\
\text { Server, Reports, Development }\end{array}$ \\
\hline 2. & Communication & $\begin{array}{l}\text { Forum, Workshop, Massages, Wikimedia, } \\
\text { Chat, Emails, Survey, Flickr, YouTube, } \\
\text { Dropbox, Bookmarks }\end{array}$ \\
\hline 3. & $\begin{array}{l}\text { Learning (Active, } \\
\text { Resource) }\end{array}$ & $\begin{array}{l}\text { Assignment, Book, Database, Folder, } \\
\text { Glossary, IMS content package, Lesson, } \\
\text { Light box Gallery, LTI, Page, Quiz, File, } \\
\text { SCORM package, URL, Workshop }\end{array}$ \\
\hline
\end{tabular}

Table III represents the framework of the e-learning management system. The features represent tools used for the process of integration learning management system with course management system.

TABLE III: FRAMEWORK OF THE LMS

\begin{tabular}{|c|c|c|c|c|}
\hline \multicolumn{5}{|c|}{ Courses } \\
\hline 1. & Accounts & Add a new user & $\begin{array}{l}\text { Add } \\
\text { Course, } \\
\text { Add group }\end{array}$ & Add/edit courses \\
\hline 2. & Permissions & $\begin{array}{l}\text { Define roles: } \\
\text { Manager Course } \\
\text { creator, } \\
\text { Administrator } \\
\text { Teacher, } \\
\text { Non-editing } \\
\text { teacher, Student, } \\
\text { Guest }\end{array}$ & $\begin{array}{l}\text { Add sub } \\
\text { categories }\end{array}$ & Add categories \\
\hline
\end{tabular}

In the following, we explain the contents of the suggested framework

1) Administrator: Users in this category have permissions to perform any function within the system.

2) Manager: Managers can access course and modify them, they usually do not participate in courses.

3) Course creator: Course creators can create new courses.

4) Teacher: Teachers can do anything within a course, including changing the activities and grading students.

5) Non-editing teacher: Non-editing teachers can teach in courses and grade students, but may not alter activities.

6) Student: Students generally have fewer privileges within a course.

7) Courses: Courses are spaces in LMS. Where teachers add learning materials for their students. Courses can be created by administrators, course creators and managers. Teachers can then add content and reorganize courses according to their own needs [21].

8) Accounts: Create profile the user and content the information personal. 


\section{B. Course Management System}

Course management system is a system used in educational institutions for the registration of students, teachers, materials, faculties, departments data and works the organization. The basic functions of the course management system are to registering classrooms, recording course material for students, teachers and administration marks, as show in Fig. 4.

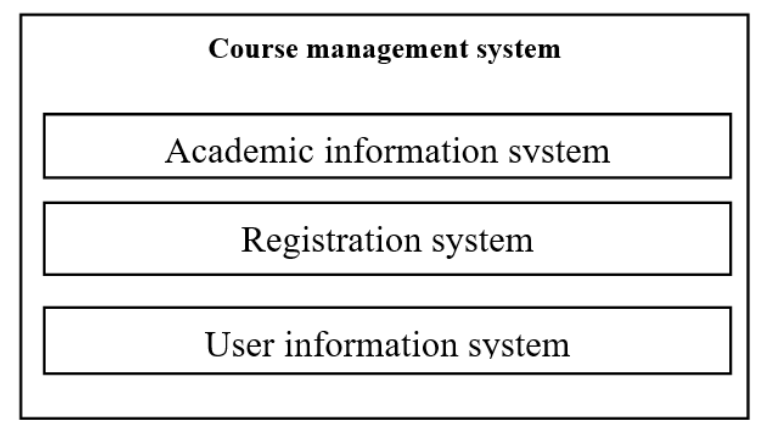

Fig. 4. Course management systems.

Academic information system: Systems process the data of course in the educational institution.

User information system (Student, teacher): A system contains personal data on students and teacher in the educational institution.

Registration system: System contains data relations to the registration of students in subjects, per semester. The data presented per semester courses, and data course teacher in the semester courses.

Fig. 4 shows the course management system. CMS is an incubator environment for the traditional education system. During the Table IV clear to the relationships that combine both teacher and student in the classroom one. Table IV shows the infrastructures to link the traditional education system (CMS) with learning management systems. Table IV shows the main features framework of the course management system that enables an integration process.

TABLE IV: FRAMEWORK OF THE COURSE MANAGEMENT SYSTEM

\begin{tabular}{|c|c|c|c|}
\hline \multicolumn{4}{|c|}{ Framework CMS } \\
\hline No. & $\begin{array}{l}\text { Academic } \\
\text { information } \\
\text { system (AIS) }\end{array}$ & $\begin{array}{l}\text { User information } \\
\text { System (UIS) }\end{array}$ & $\begin{array}{l}\text { Registration } \\
\text { system } \\
\text { (RS) }\end{array}$ \\
\hline 1. & Course schedule & Data student personal & College \\
\hline 2. & $\begin{array}{l}\text { Registrar student } \\
\text { course }\end{array}$ & Data teacher personal & Department \\
\hline 3. & $\begin{array}{l}\text { Registrar teacher } \\
\text { course }\end{array}$ & & Course \\
\hline
\end{tabular}

\section{Features of Learning Management System and Course} Management System

Learning management system that contains many of the features of the traditional education system (CMS). The course management system that contains many of the features of the learning management system. The LMS is a system used to organize and facilitate collaborative content creation. The CMS used to organize and facilitate collaborative work in the classroom. From Tables V and IV, we can see the features of learning management system and course management system.
TABLE V: COMPARE THE FEATURES CMS WITH LMS

\begin{tabular}{|llll}
\hline \multicolumn{2}{|l}{ Features in Course Management System } & & \\
\hline $\mathbf{N o}$ & Features in Course Management System & LMS & CMS \\
\hline $\mathbf{1}$ & Academic information system & - & - \\
$\mathbf{1 . 1}$ & College & - & $\mathbf{o k}$ \\
$\mathbf{1 . 2}$ & Department & - & $\mathbf{o k}$ \\
$\mathbf{1 . 3}$ & Course & ok & $\mathbf{o k}$ \\
$\mathbf{2}$ & User information system & - & - \\
\hline $\mathbf{2 . 1}$ & Data student personal & ok & $\mathbf{o k}$ \\
$\mathbf{2 . 2}$ & Data teacher personal & ok & $\mathbf{o k}$ \\
$\mathbf{3}$ & Registration system & - & - \\
\hline $\mathbf{3 . 1}$ & Course schedule & - & $\mathbf{o k}$ \\
$\mathbf{3 . 2}$ & Registrar student course & ok & $\mathbf{o k}$ \\
\hline $\mathbf{3 . 3}$ & Registrar teacher course & ok & $\mathbf{o k}$ \\
\hline & & & \\
\hline
\end{tabular}

TABLE VI: COMPARE THE USED FEATURES IN LMS WITH CMS

\begin{tabular}{|llll} 
No. & $\begin{array}{l}\text { Features in learning } \\
\text { Management System }\end{array}$ & LMS & CMS \\
\hline $\mathbf{1}$ & Users & & \\
$\mathbf{1 . 1}$ & Accounts & ok & ok \\
$\mathbf{1 . 2}$ & Permissions & ok & ok \\
$\mathbf{2}$ & Courses & ok & ok \\
$\mathbf{2 . 1}$ & Add courses & ok & ok \\
$\mathbf{2 . 2}$ & Add categories & ok & ok \\
\hline $\mathbf{2 . 3}$ & Add sub categories & & \\
\hline & & &
\end{tabular}

Course management system focuses on data management in an integrated database and used to identify the form of classroom. Table $\mathrm{V}$ shows that the learning management system involved in the management of many of the course features. The features not used in the learning management system different form and not in a different configuration.

Learning management system focuses on data management in an integrated database and used to making learning available. Table VI shows that the course management system involved in the management of many of the learning features. The features used in the learning management system same form and configuration in course management system.

The LMS and CMS can be solution based on needs of educational institution. Through clearly understanding the differences, the core functionalities of each and the benefits of combining, can help guide decision makers toward the best solution for to integration LMS and CMS.

\section{Integration of Learning Management System and Course Management System}

There are ways in which an LMS can be combined with a CMS. The methods are to incorporate features that allow traditional learning into the LMS. Among these methods, the LMS and CMS integration method was used. The integrated system allowed users logged into the LMS to access the CMS without authenticating again through the CMS. Forming a virtual classroom for each teacher, forming the academic schedule for each student and teacher. Based on what is recorded in the traditional education system. So that the student and the teacher access a virtual learning environment. Through the process of integration between systems provided by the mechanism of cooperation and integration.

Through using the new model (LIC), the advantage of this new model to exchange the information in one direction, the exchange information of the integrated system is only taken from CMS to LMS and not vice versa, through use the new model algorithm (LIC).

Algorithm 1 represent the algorithm integrates LMS and CMS and steps to apply of algorithm (LIC). 


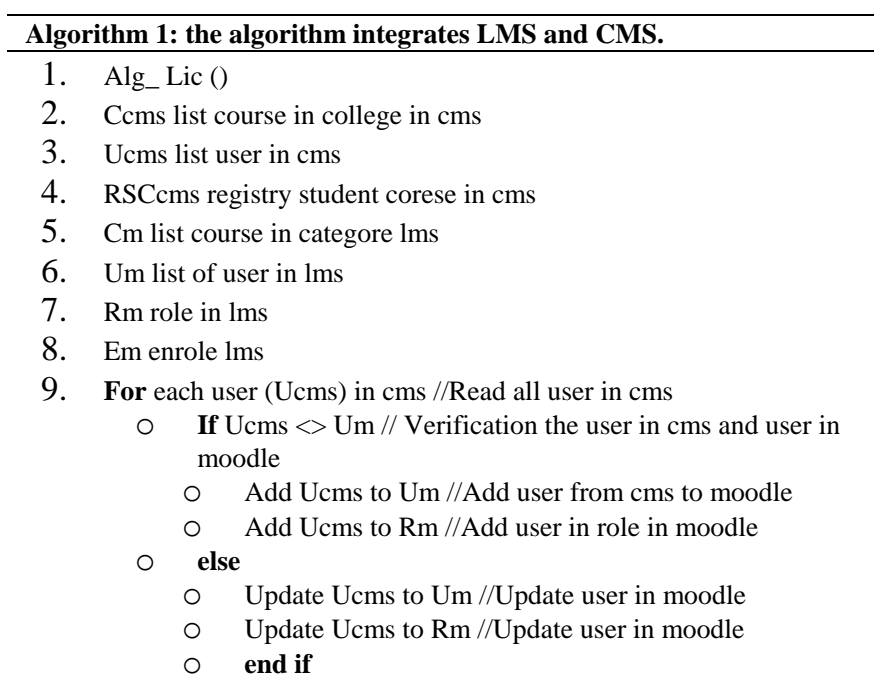

10. For each course $(\mathrm{Ccms})$ in college //Read all course in $\mathrm{cms}$

O If $\mathrm{Ccms}<>\mathrm{Cm} / /$ Verification the course in $\mathrm{cms}$ and course in moodle

- Add $\mathrm{Ccms}$ to $\mathrm{Cm} / /$ Add course from cms to moodle

○lse

O Update $\mathrm{Ccms}$ to $\mathrm{Cm} / / \mathrm{Update}$ course in moodle

$\circ$ end if

11. For each registry_student_corese (RScms) in cms //Read all registry_student_corese in $\mathrm{cms}$

O If $\mathrm{RScms}$ 《 Em // Verification the registry_student in cms and registry_student in moodle

O Add RScms to Em //Add Enrolled from cms to moodle

O Add RScms to Rm //Add roll from cms to moodle

- Else if

O Update RScms from Rm \& Em //Update Enrolled from cms to moodle

0 end if

If Um from Em $<>$ RScms // Verification the Enrolled in moodle and registry_student in cms

○ Delete Um from Rm \& Em //Delete the user in moodle from roll and enrolled

0 end if

12. next registry_student_corese // Next student

13. End Alg_Lic

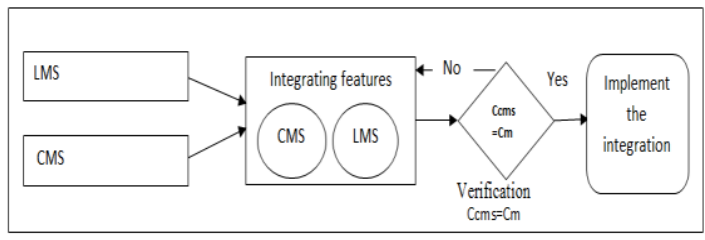

Fig. 5. Algorithm(LIC)

Steps to apply of Algorithm (LIC):

Step 1: Take the input of LMS and CMS.

Step 2: Apply the integrate algorithm (LIC).

Step 3: Conduct the verification $(\mathrm{Ccms}=\mathrm{Cm})$ of how the algorithm (LIC) integrated these two applications.

Step 4: Repeat step 2 and 3 based on the findings of the investigations in step 3. (Update the features in the integrate algorithm (LIC)).

Step 5: Implement the integration algorithm (LIC). Framework Algorithm (LIC)

LMS provides an environment allow of CMS to integrate with LMS, so that CMS part of LMS, this means that the system $\{\mathrm{CMS}\} \subset\{\mathrm{LMS}\}$.

After the integration and merge the LMS with CMS, the user (students, teachers) can share the material interactively away from the classroom so-called asynchronous education.
So that the system provides each student's educational material, the interacts teacher through the system with the students. In Fig. 6, we can see the framework of the integration of LMS and CMS.

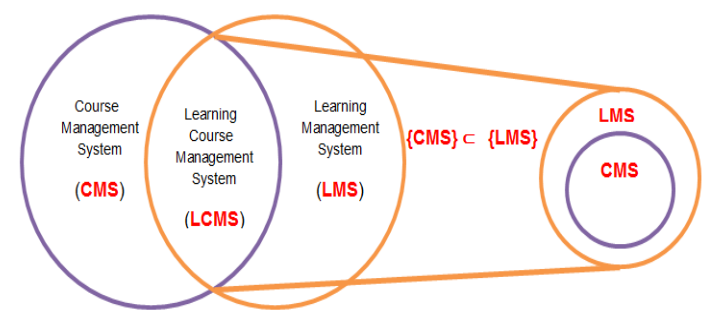

Fig. 6. Integration of CMS and LMS $-\{$ CMS $\} \subset\{$ LMS $\}$. We note from framework each (LMS, CMS) they're similar to dramatically. Can represent the some systems in the single system.

The integration should check three basic conditions so we can confrontation a lot of the difficulties in the process of selecting the features that will check us the proposed system requirements: Integration with your current course management system, scalability and flexibility. E-learning model based on course management system and learning management system in the proposed architecture, we are integrating the functionality of learning management system and course management system. Learning course management system are structured environments that are specifically designed to help organizations implement better processes and practices as they create an unlimited number of e-learning courses. Learning course management system uses the strength of course management system with the integration of learning management system.

Fig. 7 illustrates the framework of the process of integrating the learning management system and the course system, and also shows the basic elements used in the process of merging each of the two systems.

Learning management system:

User: divided into two types teacher, student.

Category: divided into sub categories, course registration and sections of these are available in the e-learning system.

Courses Management System:

User: where is divided into two students, teacher

Colleges, departments, course, course schedule and registrar student material.

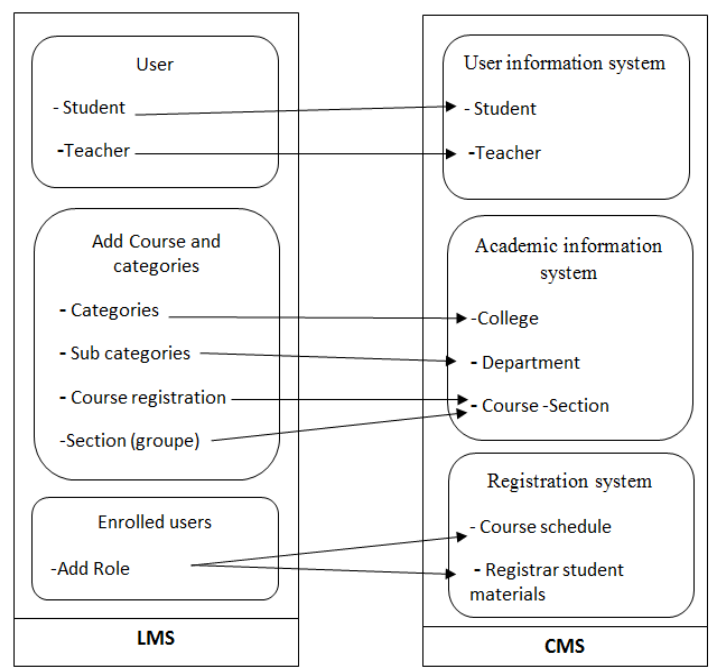

Fig. 7. Framework the algorithm (LIC). 
Will be dealing with this framework as show in Fig. 8 as follows:

Will be linked the users in each the LMS and CMS with some. Where will read the available data in the CMS, and entered into the LMS.

For example, users (students, teachers) are two stores in separate tables within the courses management system, but in the learning management system will be stored in a single table. And conducting a set of processes to enter data to learning management system, so that we can give each user's role as (student, teacher, manager, etc.).

Adding the data in the learning management system in places especially the distribution of roles. As for the faculties and departments in the courses management system, it will be handled with in the learning management system on the basis of category and sub categories.

The material in the courses management system will be handled by adding subsets within the learning management system. And students enrolled in the courses management system will handled with them in the form of members of groups within the learning management system.

Thus, we have integration the learning management system with a courses management system and the following illustrates implementation.

\section{E. Implementation the Algorithm (LIC)}

Fig. 8 represents the model (LIC) used in integration learning management system and course management system. Through a series of processes such as add users (students and teachers), course materials, classified (faculties, departments). Users by the distribution of authorities on the materials and the people of study (groups). So that the merging process takes place in the following order:

1) User (Students. teacher).

2) Material.

3) Presented material.

4) Distribution of materials on the students and teachers.

5) Give authorities (the validity of student, the validity of teacher).

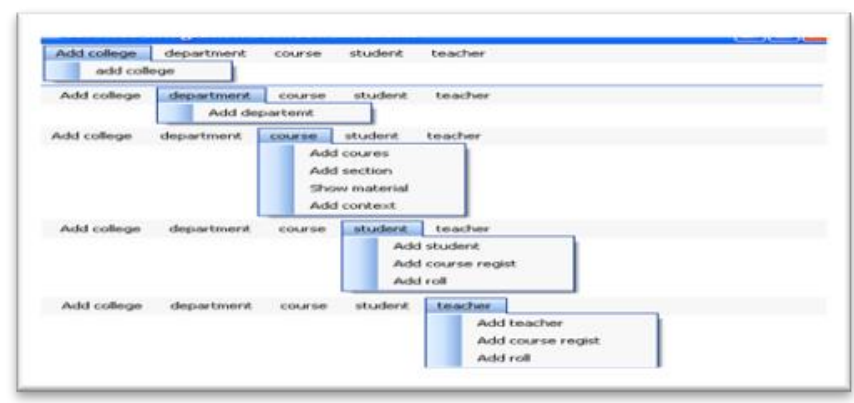

Fig. 8. Screen the implementation algorithm (LIC).

\section{F. Case Study of the Algorithme (LIC)}

The author used the learning management system (Moodle), traditional education (course management system) and apply the algorithm (LIC).

The Fig. 9 represent the course management system. That is material from which the data in the student wishes studied, in the classroom where the course management system represents the means by which the composition of the classroom (traditional education classes).

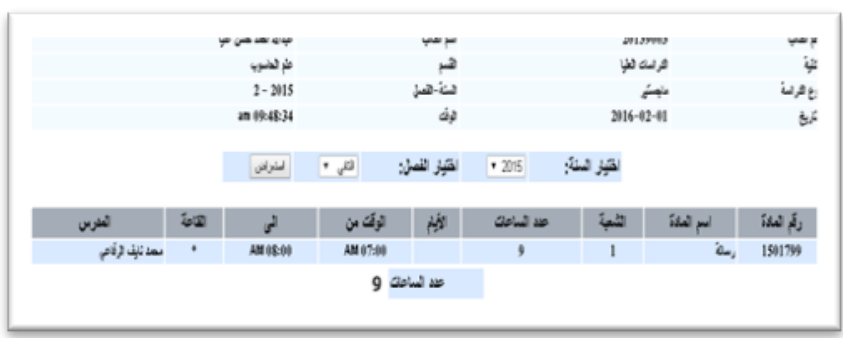

Fig. 9. Screen course management systems.

Fig. 10 represents the learning management system, where the material data in which the student wishes to study, in the classroom where Fig. 10 shows that the shows reflect the classroom (traditional education classes) to become virtual classes. The reality of the educational process in traditional education classes simulates the electronic process. In addition to not be selected location or time to educational process (non-synchronous education).

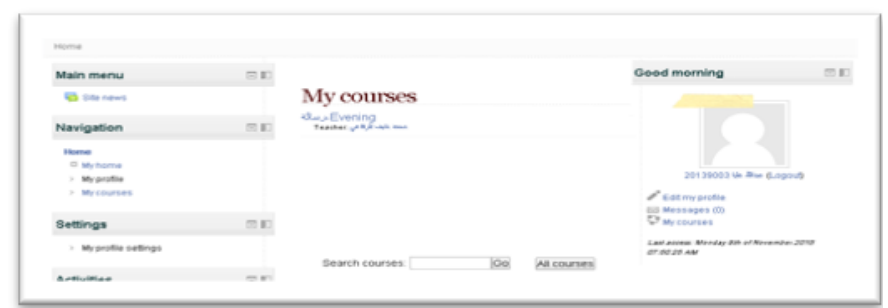

Fig. 10. Screen learning management system.

Fig. 10 represent the Enrolled user in learning management system. Where the students enrolled course section posted in the classroom. Include name of user (student and teacher), last access, roles and group (section in CMS).

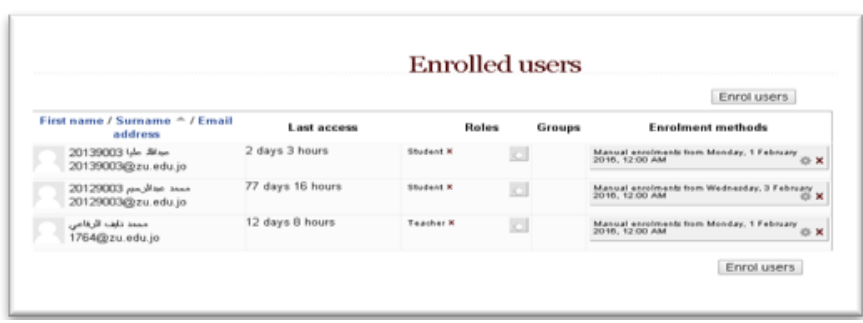

Fig. 11. Screen enrolled user in learning management system.

Figs. 10 and 11 represents the result of the integration process CMS and LMS used the LIC show in Fig. 8. The Fig. 9 show student registry the course in traditional education and Fig. 11 show reflects the course in LMS.

\section{G. USED (LIC)}

User (students, teacher) who have registered material data to be studied in the classroom using the course management system. An account is created for the user (students, teacher) of the learning management system appear materials that they registration previously on the course management system. Where students will be grouped with some of the material according to the group to which they belong with their teacher. And then the students will benefit from the services that will be provided by the teacher through the learning management system. To login to the integrated system, the users using login used at CMS to access the LMS. 


\section{H. Ethical Considerations}

The process portfolio of privacy for students who have signed up material data to be studied in the classroom using the course management system. All the processes taking place in the learning management system for one system cannot be seen from the students, and the person authorized to see it is the owner of the account and the course teacher only. Taking into account cultural diversity and different forms of learning depending on the learners and their culture, their location and special needs. For example, marks obtained by the student from activities such as exams and other activities are taken into consideration. No one can be seen whether person concerned (student only).

\section{RESUlT}

Results in the initial integration step, it obtained on new module (LIC) Working on integration course management system and learning management system, as shown in Fig. 9, where he was reached by the new module (LIC) to the set of results are as follows:

When CMS and LMS work in parallel on the same data, you can automatically synchronize and easily manage accounts, users, courses, and distribution the (course and user). There is no need to manually input the data in two different systems. This increases the value of used the learning management system by improving time and accuracy, as show in the result TABLE VII: and Figs. 9-10.

1) Reduce the time in create educational materials within the LMS.

2) Accuracy in the creation of educational materials within the LMS.

3) Accuracy in the distribution of students and teachers on the course.

4) Configure class room inside the LMS that matches the CMS by one hundred percent. Where include materials, sections, colleges and users (students, teachers).

The experiments are conducted in a system with configuration Intel ${ }^{\circledR}$ Core $^{\mathrm{TM}}$ i7 Processor, 16 GB DDR3 Memory and 500 GB HDD. Experiments recorded the result, as show in the result TABLE VII.

TABLE VII: RESULTS IN THE INITIAL INTEGRATION

\begin{tabular}{|c|c|c|c|}
\hline \multicolumn{4}{|l|}{ RESULT } \\
\hline \multirow[b]{2}{*}{ Tasks } & \multirow{2}{*}{$\begin{array}{l}\text { Number } \\
\text { of row in DB }\end{array}$} & \multicolumn{2}{|l|}{ Time run } \\
\hline & & Manual (CSV) & LIC \\
\hline User data & 6738 & 15 mints & 2.0 second \\
\hline College & 15 & 7.30 mints & 4.3 second \\
\hline Department & 83 & $41.3 \mathrm{mints}$ & 8.4 second \\
\hline Course & 808 & 215.4 mints $/ 3.08 \mathrm{H}$ & 48 second \\
\hline $\begin{array}{l}\text { Distribution } \\
\text { userto course }\end{array}$ & 38032 & 69.4 mints $/ 1.156 \mathrm{H}$ & 30 mints \\
\hline
\end{tabular}

Table VII shows the results enter data through the new model (LIC) process has achieved positive results, compared with the old method adopted by Excel files (CSV), where the teams table shows the time the user and thus achieved a speed in the process of e-learning systems processing, and accuracy. Will be computerized business more accurate from business handicrafts. The following explanation of the Table VII.

Users enter data for the system process took time estimated
2 seconds through the use of new module(LIC), taken either in the old time of 15 minutes when insert 6738 user, and college enter data for the system process took time estimated 4.3 seconds through the use of new module (LIC) ,taken either in the old time of 7.30 minutes when insert 15 college, and department enter data for the system process took time estimated 8.4 seconds through the use of new module(LIC) ,taken either in the old time of 41.3 minutes when insert 83 department, and course enter data for the system process took time estimated 48 seconds through the use of new module(LIC), taken either in the old time of 215.4 minutes when insert 808 course , and distribution user to course enter data for the system process took time estimated 30 minutes through the use of new module(LIC), taken either in the old time of 69.4 minutes when insert 38032 distribution user to course.

\section{Conclusion (LIC)}

This article presents an empirical study of the characteristics of LMS platforms and CMS. The study was conducted in four parts The first step is the process of eliciting requirements and discussing e-learning systems analysis criteria, in the second step the discussion of the CMS course management analysis criteria.in the three steps, a study features of learning management system and course management system and identify the features of the learning management system and the course management system and identify the common features. and in the four steps, Integration Of learning management system and course management system.

\section{CONFLICT OF INTEREST}

The authors declare no conflict of interest.

\section{REFERENCES}

[1] (2015). CedefopEuropean-inventory-glossary. [Online]. Available: http://www.cedefop.europa.eu/en/events-and-rojects/projects/validatio n-non-formal-and-informal-learning/european-inventory/european-inv entory-glossary

[2] (December 2015). Codecall8-best-open-source-e-learning-cms. [Online]. Available: http://codecall.net/2019/05/16/8-best-open-source-e-learning-cms

[3] W. Horton and K. Horton, "E-learning Tools and Technologies: A consumer's guide for trainers, teachers, educators, and instructional designers," John Wiley \& Sons, 2003.

[4] R. C. Clark and R. E. Mayer, "E-learning and the science of instruction: Proven guidelines for consumers and designers of multimedia learning," John Wiley \& Sons, 2011.

[5] H. Canales and F. Garcia, E-Learning Platforms. Communication Software Laboratory Academic, 2007-2008.

[6] R. Rabiman, M. Nurtanto, and N. Kholifah, "Design and development e-learning system by learning management system (lms) in vocational education'," International Journal of Scientific and Technology Research, vol. 9, no. 1, pp. 1059-1063, 2020.

[7] A. A. Sejzi and B. Arisa, "Learning management system (LMS) and learning content management system (LCMS) at virtual university," presented at 2nd International Seminar on Quality and Affordable Education (ISQAE), Johor, Malaysia, December, 2013.

[8] A. Muhammad, "Developing an e-learning system (course repository)," Registration number: - Zu/Bba/4181/11, 15 July 2014.

[9] Moodle. (October 2019). [Online]. Available http://www.moodle.org

[10] J. Rožac, F. Buendía, J. Ballester, A. Kos, and M. Pogačnik, "Integration of learning management systems with social networking platforms," in Proc. the Fourth International Conference on Mobile, Hybrid, and On-line Learning," pp. 100-105, 2012. 
[11] (December 2019). Trainingforce. What_is_a_lms. [Online]. Available: http:// www.trainingforce.com/content/what_is_a_lms.aspx

[12] (December 2019). Searchcio.techtargetLearning-management-system. [Online]. Available: http://searchcio.techtarget.com/definition/learning-management-syste $\mathrm{m}$

[13] N. Cavus and T. Zabadi, "A comparison of open source learning management systems," Procedia-Social and Behavioral Sciences, vol. 143 , pp. 521-526, 2014.

[14] A. Guelfi et al., "in methodologies," tools and new developments for e-learning" more like this, book edited by pontes," InTech. 41 Madison Avenue 31st Floor, New York, NY 10010, 2012.

[15] (December 2015). Tutorialspoint.Content_management_system. [Online]. Available: http://www.tutorialspoint.com/management_information_system/cont ent_management_system.htm

[16] K. Tuli, "Course management system - A planning for technologies," International Journal of Advanced Research in IT and Engineering, vol. 3, no. 5, May 2018.

[17] J. Meerts, "Course management systems (CMS). Educause evolving technologies committee," Wesleyan University, October 2003.

[18] S. Muzafer "Virtual learning environment and future of e-learning in enterprises," UNITE: University Journal of Information Technology and Economics, vol. 1, no. 2, 2015.

[19] T. Jurubescu, "Learning content management system," Revista Informatica Economica, vol. 4, no. 48, pp. 91-94, 2008.

[20] H. Fawareh and A. Alia. "Analysis of e-learning system in the presence of social requirement," International Journal of Engineering \&Technology, vol. 7, no. 4, pp. 6534-6538, 2018.
[21] Jacobsen.PLMS vs.LCMS. (2002). [Online]. Available: http://www.elearningmag.com/ltimagazine/article/articleDetail.jsp?id $=21264$

[22] B. Cremers and S. Alda. "Organizational. Requirements engineering. Chapter 5. Requirements engineering. (Requirements elicitation I)," November 2015.

[23] A. David, "Back other Learning management system and e-learning tools: an experience of medical students' usage and expectations," 2019.

[24] S. D. Lonn, "Student use of a learning management system for group projects: A case study investigating interaction, collaboration, and knowledge construction," Doctoral dissertation, The University of Michigan. 2009.

Copyright $(\odot) 2022$ by the authors. This is an open access article distributed under the Creative Commons Attribution License which permits unrestricted use, distribution, and reproduction in any medium, provided the original work is properly cited ( $\underline{\text { C BY 4.0). }}$.

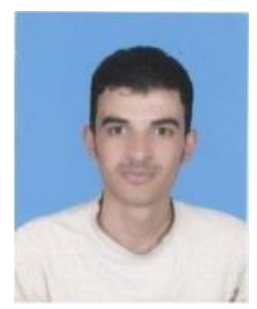

Abdullah Ahmed Hassan Alia is a lecturer \& developer at the e-Learning Center, Zarqa University. $\mathrm{He}$ received the bachelor's degree in computer science from Zarqa University-Jordan, and the master's degree in computer science from Zarqa University-Jordan. His research interests include in field educational technology. 